\title{
PRODUÇÃO E QUALIDADE DE SEMENTES DE BERINJELA EM FUNÇÃO DO HORÁRIO DE POLINIZAÇÃO MANUAL ${ }^{(1)}$
}

\author{
MARIANA RIOS POLVERENTE ${ }^{(2)}$; DIEGO CARNEIRO FONTES ${ }^{(2)}$; \\ ANTONIO ISMAEL INÁCIO CARDOSO (2)
}

\begin{abstract}
RESUMO
O experimento foi desenvolvido na área experimental do Departamento de Produção Vegetal, setor de Horticultura, da Faculdade de Ciências Agronômicas (FCA), Universidade Estadual Paulista (UNESP), Câmpus Botucatu, com o objetivo de avaliar a produção e qualidade de sementes de berinjela (cultivar Embu), em função de diferentes horários de polinização. O delineamento experimental foi em blocos ao acaso, com sete tratamentos (polinização manual às $7 \mathrm{~h} ; 9 \mathrm{~h} ; 11 \mathrm{~h} ; 13 \mathrm{~h} ; 15 \mathrm{~h}$; testemunha 1 = polinização natural, sem proteção da flor e testemunha 2 = polinização natural com proteção da flor com saco de papel), com quatro repetições e seis plantas por parcela. Obteve-se menor produção e qualidade das sementes quando a flor foi previamente protegida. Com a polinização natural, sem proteção da flor, os resultados foram mais elevados aos das polinizações manuais, com maior massa, comprimento, diâmetro dos frutos e produção de sementes por fruto. A polinização natural, sem proteção da flor, possibilitou, ainda, a obtenção de sementes com similares germinação e vigor em relação aos demais processos.
\end{abstract}

Palavras-chave: Solanum melongena L., polinização natural.

\section{ABSTRACT \\ EGGPLANT SEED PRODUCTION AND QUALITY IN DIFFERENT TIMES OF MANUAL POLLINATION}

The experiment was carried out at Vegetal Production Department, Horticulture subdivision, Universidade Estadual Paulista, aiming to evaluate the production and quality of eggplant seed (cultivar Embu) when pollination was conducted at different times of the day. The experimental design was a randomized block, with seven treatments (7:00am, 9:00am, 11:00am, 1:00pm, 3:00pm, control 1= natural pollination, no flower protection and control $2=$ natural pollination with flower protection with paper bags), with four replications and six plants per plot. Lower production and quality of seeds were obtained when flowers were previously protected. Natural pollination, with no flower protection, showed superior results when compared to manual pollination, with larger weight, length and diameter of fruits and bigger seed production per fruit. Natural pollination, with no flower protector, enabled, also, to obtain of seeds with similar germination and vigor compared to other processes.

Key words: Solanum melongena L., natural pollination.

( $\left.{ }^{1}\right)$ Recebido para publicação em 4 de maio de 2004 e aceito em 5 de maio de 2005.

( $\left.{ }^{2}\right)$ Departamento de Produção Vegetal - Horticultura, Faculdade de Ciências Agronômicas, Universidade Estadual Paulista, Caixa Postal 237, 18603-970 Botucatu (SP). E-mail: mrpolverente@fca.unesp.br; ismaeldh@fca.unesp.br 


\section{INTRODUÇÃO}

Híbridos comerciais de berinjela (Solanum melongena L.), desenvolvidos por hibridação de variedades nos últimos 15 anos, têm alcançado prestígio comercial, pela heterose proporcionar incrementos nos componentes de produção, maior precocidade e alterações benéficas na altura da planta (Poulos, 1994; MAluf, 2001). Em berinjela, a heterose vem sendo explorada economicamente, principalmente pela facilidade na obtenção de sementes híbridas, por apresentar órgãos florais grandes, facilitando o trabalho de castração e polinização controlada (CARDOso, 2001), amplo período de florescimento e ao elevado número de sementes por fruto (MALUF, 2001).

De acordo com GEORGE (1999), a produção de sementes híbridas em Solanáceas, envolve a manutenção de duas linhas parentais de plantas separadas, ou seja, os parentais masculinos e femininos. O masculino é usado como doador de pólen e o feminino como receptor do pólen e, subseqüentemente, produz frutos contendo as sementes híbridas. As flores na linha feminina vão ser emasculadas durante o estádio de botão em preparação para a polinização manual. As anteras são completamente removidas por meio de uma pinça.

O desenvolvimento das plantas e a fixação dos frutos e sementes dependem das condições ambientais. A berinjela é uma das hortaliças mais exigentes em temperatura elevada, com alta sensibilidade ao frio e à geada, porém, durante a floração e a frutificação, tolera temperaturas mais amenas. Quando a temperatura é de $15^{\circ} \mathrm{C}$, ou menor, o crescimento da planta é lento, sendo 23 a $26^{\circ} \mathrm{C}$ mais favorável. Acima de $35^{\circ} \mathrm{C}$ pode ocorrer o abortamento das flores com redução na produtividade (FILGUeIRA, 2000).

Observou-se que, em tomateiro, em altas temperaturas do ar $\left(28^{\circ} \mathrm{C}\right)$, ocorre menor formação de frutos por cachos, em comparação a temperaturas médias de $22{ }^{\circ} \mathrm{C}$ durante o dia. Esse fato é explicado pela protusão do estigma, resultando em insucesso na polinização e pelo lento crescimento do tubo polínico. No caso de haver polinização, resulta em menor fixação de fruto (Peterson e Taber, 1987, citados por Martins, 1992). Também, Lohar e Peat (1998), verificaram que a protusão do estigma em altas temperaturas $\left(28 / 23^{\circ} \mathrm{C}\right)$, resultou em menor fixação dos frutos. Já em berinjela, segundo Sun et al. (1990), a faixa ideal para a fixação dos frutos ocorre entre 28 e $34{ }^{\circ} \mathrm{C}$ e, quanto mais baixa a temperatura dentro desta faixa, menor é a fixação. Sabe-se que a temperatura oscila ao longo do dia; entretanto, não há relatos sobre a influência do horário em que se realiza a polinização manual sobre a fixação de frutos e a produção de sementes em berinjela.

O objetivo deste trabalho foi avaliar a produção e qualidade de sementes de berinjela em função dos diferentes horários de polinização.

\section{MATERIAL E MÉTODOS}

O experimento foi realizado em sistema de ambiente protegido (cobertura plástica) na área experimental da Faculdade de Ciências Agronômicas (FCA), UNESP - Câmpus de Botucatu. A área está localizada em altitude de $800 \mathrm{~m}$ do nível do mar, com uma longitude Oeste $48^{\circ} 26^{\prime} 37^{\prime \prime}$ e latitude Sul $22^{\circ} 52^{\prime}$ 20 ". O tipo climático, segundo Köeppen, é o Cwb (mesotérmico de inverno seco).

As semeaduras para obtenção de mudas foram realizadas em $24 / 2 / 03$ para as plantas consideradas como parental masculino, e em 13/03/03 para as plantas consideradas como parental feminino. Foi utilizada a cultivar Embu, por ser uma das poucas variedades disponíveis no mercado.

Os transplantes das mudas foram realizados em 27/3/03 (parental masculino) e 16/4/03 (parental feminino) no espaçamento de $1,0 \times 0,5 \mathrm{~m}$. A adubação constou de $143 \mathrm{~g}$ de calcário, $143 \mathrm{~g}$ de N-P-K (4-14-8) e 1,8 litros de composto orgânico (Biomix ${ }^{\circledR}$ ) por $\mathrm{m}^{2}$ da estufa.

Foram realizadas adubações em cobertura a cada sete dias, utilizando-se 2 gramas/planta de nitrato de potássio, visando disponibilizar a quantidade de potássio, em cobertura, recomendada para a cultura no Boletim 100 (TrANI et al., 1996), apenas com maior parcelamento da quantidade recomendada.

Os tratamentos fitossanitários foram efetuados conforme a necessidade da cultura, e a irrigação utilizada foi por gotejamento.

Foram avaliados sete tratamentos: polinização manual em diferentes horários (7h, 9h, 11h, 13h e $15 \mathrm{~h}$ ); testemunha 1 (polinização natural, sem proteção da flor) e testemunha 2 (polinização natural, com proteção da flor com saco de papel antes da antese). O delineamento experimental foi em blocos ao acaso, com quatro repetições, sendo cada parcela constituída por seis plantas.

Para evitar que ocorresse autofecundação natural, nos tratamentos com polinização manual, as flores foram emasculadas no estádio de botão floral (GEORGE, 1999), um dia antes da antese e as flores não polinizadas foram eliminadas. Após a emasculação, 
as flores foram protegidas com um saco de papel que permaneceu envolvendo-as, mesmo depois de realizada a polinização manual.

As polinizações manuais foram efetuadas em várias flores de cada planta, deixando apenas dois frutos por planta. Nas polinizações naturais (testemunhas 1 e 2) também foram deixados dois frutos por planta para avaliar o potencial de produção e qualidade de sementes por fruto. A flor da primeira bifurcação não foi utilizada, pois o fruto fixado nessa posição pode prejudicar o desenvolvimento da planta e a fixação de novo fruto.

As polinizações manuais foram realizadas em 3/7/03,8/7/03, 9/7/03,13/7/03,16/7/03,17/7/ $03,18 / 7 / 03$ e $20 / 7 / 03$. Foram observadas as seguintes temperatura e umidade relativa médias em cada horário: $7 \mathrm{~h}\left(15,5^{\circ} \mathrm{C} ; 85,9 \%\right), 9 \mathrm{~h}\left(25,7^{\circ} \mathrm{C} ; 64,9 \%\right)$, $11 \mathrm{~h}\left(27,6{ }^{\circ} \mathrm{C} ; 58,3 \%\right)$, $13 \mathrm{~h}\left(31,9^{\circ} \mathrm{C} ; 53,1 \%\right)$ e $15 \mathrm{~h}(32,1$ $\left.{ }^{\circ} \mathrm{C} ; 55,1 \%\right)$.

Foram realizadas três colheitas $(18 / 9 / 03,25 /$ 9/03 e 2/10/03), quando os frutos estavam, em média, com 74 dias após a abertura da flor. Depois da colheita, os frutos foram pesados, mediu-se seu comprimento, diâmetro maior e menor. Posteriormente, suas sementes foram retiradas e colocadas para secar em pratos de barro em condições de laboratório.

Foram avaliadas as seguintes características: porcentagem de fixação de frutos, massa do fruto, comprimento do fruto, diâmetro maior e menor do fruto, produção (massa e número) de sementes por fruto, massa de 1.000 sementes e qualidade das sementes (germinação e vigor).

As sementes foram armazenadas em câmara seca $\left(20^{\circ} \mathrm{C}\right.$ e $40 \%$ de umidade relativa) até que o teor de água se estabilizasse em $8 \%$. A germinação foi avaliada de acordo com as Regras de Análise de Sementes. Para isso, 100 sementes de cada parcela foram colocadas para germinar em caixas gerbox, com papel especial para germinação - germitest, e levadas à B.O.D., com temperatura de $20^{\circ} \mathrm{C}$ por 12 horas, alternada com $30^{\circ} \mathrm{C}$ por outras 12 horas (BRASIL, 1992). Foram realizadas contagens aos sete e aos 14 dias, sendo a primeira contagem utilizada como teste de vigor. Também foi obtido o índice de velocidade de germinação, com contagens diárias no teste de germinação até o $14 .^{\circ}$ dia, conforme descrito por MAGUiRE (1962), sendo calculado segundo a fórmula:

$$
\mathrm{IVG}=\frac{\mathrm{N} 1}{\mathrm{D} 1}+\frac{\mathrm{N} 2}{\mathrm{D} 2}+\ldots . \frac{\mathrm{Nn}}{\mathrm{Dn}}
$$

em que:

IVG = Índice de velocidade de germinação.

$\mathrm{N} 1, \mathrm{~N} 2$....Nn = número de plântulas normais computadas na primeira contagem, na segunda contagem, até a última contagem.
D1, D2 ...Dn = número de dias da semeadura à primeira contagem, segunda contagem e última contagem. Após a análise de variância, as médias foram comparadas pelo teste de Tukey a 5\% de probabilidade. Para a característica número de sementes por fruto, a análise foi realizada com transformação dos dados em raiz quadrada.

\section{RESULTADOS E DISCUSSÃO}

\subsection{Características do fruto}

Observou-se maior massa nos frutos na condição de polinização natural, sem proteção da flor (testemunha 1), sendo superior a todos os demais tratamentos (Tabela 1). Com isolamento da flor com o saco (testemunha 2), foram obtidos frutos com a menor massa e número de sementes por fruto relativamente ao tratamento 1 (Tabela 2). Também DEMPSEY e BOYNTON (1965), em tomate, e Marcelis e Hofman-Eijer (1997), em pimentão, relataram maior massa e tamanho dos frutos quanto maior o número de sementes. Provavelmente a grande visitação pelos insetos favoreça a deposição de maior quantidade de pólen e possibilitando maior quantidade de sementes. Sementes em desenvolvimento produzem fitoreguladores, possivelmente auxinas, que estimulam o crescimento dos frutos (BEYER e QUEBEDEAUX, 1974; KIM et al., 1992), resultando em frutos maiores.

Em relação ao comprimento e diâmetro dos frutos, observou-se a mesma tendência para a massa, ou seja, testemunha 1 com maiores valores (Tabela 1 ). Também em pimentão, foi relatado que a polinização por insetos afetou a massa, o comprimento e tamanho dos frutos, com obtenção de frutos maiores na presença de insetos em comparação à ausência (SHIPP et al.,1994). Não se observaram diferenças significativas para essas características do fruto (massa, comprimento e diâmetro) entre os tratamentos com polinização manual (Tabela 1). A polinização natural por insetos favoreceu o desenvolvimento e crescimento dos frutos.

\subsection{Fixação de frutos e produção de sementes}

Não houve diferença significativa entre os tratamentos com polinização manual em relação à fixação dos frutos (Tabela 2). Segundo Sun et al. (1990), a faixa ideal para fixação dos frutos de berinjela ocorre entre 28 e $34^{\circ} \mathrm{C}$, e quanto mais baixa a temperatura dentro dessa faixa menor é a fixação. Ressalta-se que as polinizações foram realizadas em julho, mês geralmente com temperaturas amenas. 
Tabela 1. Massa, comprimento e diâmetros de frutos de berinjela nos diferentes tratamentos. Botucatu (SP), FCA-UNESP, 2003

\begin{tabular}{|c|c|c|c|c|}
\hline Tratamentos & Massa & Comprimento & Diâmetro maior & Diâmetro menor \\
\hline & $\mathrm{g} /$ fruto & 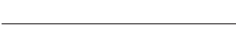 & $\mathrm{cm}$ & 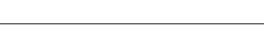 \\
\hline $7 \mathrm{~h}^{(1)}$ & $420 \mathrm{bc}$ & $18,22 \mathrm{~b}$ & $8,16 \mathrm{bc}$ & $5,69 \mathrm{~b}$ \\
\hline $9 \mathrm{~h}$ & $542 \mathrm{~b}$ & $18,91 \mathrm{~b}$ & $9,07 \mathrm{ab}$ & $6,64 \mathrm{ab}$ \\
\hline $11 \mathrm{~h}$ & 529 bc & $19,18 \mathrm{~b}$ & $9,07 \mathrm{ab}$ & $6,79 \mathrm{ab}$ \\
\hline $13 \mathrm{~h}$ & $545 \mathrm{~b}$ & $19,02 \mathrm{~b}$ & $8,95 \mathrm{ab}$ & $6,82 \mathrm{ab}$ \\
\hline $15 \mathrm{~h}$ & $471 \mathrm{bc}$ & $18,23 \mathrm{~b}$ & $8,92 \mathrm{~b}$ & $6,38 \mathrm{ab}$ \\
\hline $\mathrm{T} 1^{(2)}$ & 858 a & $25,01 \mathrm{a}$ & $10,50 \mathrm{a}$ & $7,57 \mathrm{a}$ \\
\hline $\mathrm{T} 2^{(3)}$ & $301 \mathrm{c}$ & $16,72 \mathrm{~b}$ & $7,20 \mathrm{c}$ & $5,87 \mathrm{~b}$ \\
\hline C.V. \% & 18,8 & 9,4 & 7,6 & 8,3 \\
\hline
\end{tabular}

( $\left.{ }^{1}\right)$ Horários de polinização manual.

$\left({ }^{2}\right) \mathrm{T} 1=$ testemunha1 (polinização natural, sem proteção da flor).

$\left({ }^{3}\right) \mathrm{T} 2=$ testemunha2 (polinização natural, com proteção da flor).

Médias seguidas pela mesma letra, nas colunas, não diferem estatisticamente pelo teste de Tukey a 5\% de probabilidade.

Tabela 2. Taxa de fixação dos frutos, massa de sementes por fruto, número de sementes por fruto (NrSemFr) e massa de 1.000 sementes de berinjela nos diferentes tratamentos. Botucatu (SP), FCA - UNESP, 2003

\begin{tabular}{|c|c|c|c|c|}
\hline Tratamentos & Fixação dos frutos & Massa de sementes & $\mathrm{NrSemFr}$ & Massa de 1.000 sementes \\
\hline & $\%$ & $\mathrm{~g} /$ fruto & & $\mathrm{g}$ \\
\hline $7 \mathrm{~h}^{(1)}$ & $66 \mathrm{~b}$ & $0,84 \mathrm{~b}$ & $125 \mathrm{~b}$ & $6,71 \mathrm{a}^{(4)}$ \\
\hline $9 \mathrm{~h}$ & $60 \mathrm{~b}$ & $2,67 \mathrm{~b}$ & $467 \mathrm{~b}$ & $6,07 \mathrm{a}$ \\
\hline $11 \mathrm{~h}$ & $83 \mathrm{~b}$ & $3,23 \mathrm{~b}$ & $707 \mathrm{~b}$ & $5,62 \mathrm{a}$ \\
\hline $13 \mathrm{~h}$ & $74 \mathrm{~b}$ & $1,92 \mathrm{~b}$ & $305 \mathrm{~b}$ & $6,88 \mathrm{a}$ \\
\hline $15 \mathrm{~h}$ & $70 \mathrm{~b}$ & $1,50 \mathrm{~b}$ & $255 \mathrm{~b}$ & $6,52 \mathrm{a}$ \\
\hline $\mathrm{T} 1{ }^{(2)}$ & $100 \mathrm{a}$ & 9,73 a & 2108 a & $4,66 \mathrm{a}$ \\
\hline $\mathrm{T} 22^{(3)}$ & $88 \mathrm{ab}$ & $0,39 \mathrm{~b}$ & $77 \mathrm{~b}$ & $5,94 \mathrm{a}$ \\
\hline C.V.(\%) 15,1 & 42,1 & 38,6 & 17,3 & \\
\hline
\end{tabular}

( $\left.{ }^{1}\right)$ Horários de polinização manual.

( $\left.{ }^{2}\right) \mathrm{T} 1=$ testemunha1 (polinização natural, sem proteção da flor).

$\left({ }^{3}\right)$ T2 = testemunha2 (polinização natural, com proteção da flor).

Médias seguidas pela mesma letra, nas colunas, não diferem estatisticamente pelo teste de Tukey a 5\% de probabilidade.

Na testemunha 1, houve a maior fixação (Tabela 2), superior a todos os tratamentos com polinização manual, exceto à testemunha 2.

Observou-se, nesse experimento, que várias flores tinham o estigma fora do cone de anteras, o que pode ser a causa da redução na fixação de frutos na testemunha 2. Segundo PASSAM et al. (2001), estigmas para fora do cone de anteras podem prejudicar a autofecundação das flores, reduzindo a fixação na ausência de insetos. Essa ocorrência também foi relatada para pimentão por SHIPP et al. (1994) que observaram maior fixação e maior tamanho dos frutos com a presença de insetos polinizadores.

A produção de sementes por fruto, em massa e número, foi maior nos frutos com polinização natural, sem proteção (testemunha 1); não houve 
diferença significativa entre os tratamentos com polinizações manuais e a natural com proteção (Tabela 2). É possível que o manuseio das flores ou a colocação do pólen possa afetar negativamente os órgãos florais femininos, reduzindo a produção de sementes por fruto. Também é possível que na polinização natural, devido à grande visitação pelos insetos, obtenha-se a deposição de maior quantidade de pólen, possibilitando maior quantidade de sementes, sendo muito comum em diversas espécies alógamas como as cucurbitáceas (Ávila et al., 1989; SChlichiting et al., 1987; Stephenson et al., 1988). A berinjela geralmente é classificada como autógama (Filgueira, 2000; George, 1999), porém verifica-se a importância da fecundação cruzada realizada por insetos na produção de sementes dessa cultivar. Ressalta-se que a área experimental é muito visitada por abelhas (Apis mellifera) e que as laterais das casas de vegetação ficaram abertas por todo o ciclo, permitindo o livre acesso aos insetos polinizadores.

Apesar de menor número de sementes quando se protegeu a flor (testemunha 2), a fixação de frutos, nesse tratamento, não foi muito prejudicada (Tabela 1), mostrando a eficiência da autofecundação natural.

\subsection{Qualidade das sementes}

Não foram observadas diferenças significativas entre os tratamentos para a massa de 1.000 sementes (Tabela 2). Ressalta-se que foram obtidas médias superiores a 5 gramas, valor relatado por GeORGE (1999), para a massa média de 1.000 sementes de berinjela.

Quanto aos índices de vigor (primeira contagem e índice de velocidade de germinação), a polinização manual realizada às $9 \mathrm{~h}$ foi superior apenas à realizada às $15 \mathrm{~h}$, na primeira contagem, à polinização realizada às $11 \mathrm{~h}$ e à testemunha 2 para o índice de velocidade de germinação. Quanto à germinação, as sementes originárias de polinização natural, com proteção de flor, testemunha 2 , foi inferior às polinizações manuais realizadas às 7,9 e $13 \mathrm{~h}$, não diferindo da testemunha 1 . Não ocorreram diferenças entre os tratamentos com polinização manual e a polinização natural sem proteção da flor para todos os índices, assim como entre as polinizações naturais, com e sem proteção das flores.

Os coeficientes de variação relativamente elevados observados para índices de qualidade de sementes (Tabela 3) podem ter ocorrido pelo fato de, embora estas análises (massa de 1.000 sementes e testepadrão de germinação) serem realizadas em condições controladas de laboratório, as sementes avaliadas foram obtidas em condições de campo. A "desuniformidade" entre as repetições do mesmo tratamento que resulta em elevação no coeficiente de variação, foi devido a fatores ambientais no decorrer do desenvolvimento dos frutos e na extração das sementes. Portanto, o teste-padrão de germinação apenas refletiu os resultados obtidos em condições menos controladas.

Tabela 3. Primeira contagem, germinação padrão e índice de velocidade de germinação (IVG) das sementes de frutos de berinjela nos diferentes tratamentos. Botucatu (SP), FCA-UNESP, 2003

\begin{tabular}{lccc}
\hline Tratamentos & Germinação padrão & Primeira contagem & IVG \\
\cline { 2 - 4 } $7 \mathrm{~h}^{(1)}$ & $91,7 \mathrm{a}$ & $68,0 \mathrm{ab}$ & $14,8 \mathrm{ab}$ \\
$9 \mathrm{~h}$ & $97,5 \mathrm{a}$ & $80,3 \mathrm{a}$ & $16,7 \mathrm{a}$ \\
$11 \mathrm{~h}$ & $78,7 \mathrm{ab}$ & $39,3 \mathrm{ab}$ & $10,5 \mathrm{~b}$ \\
$13 \mathrm{~h}$ & $97,0 \mathrm{a}$ & $66,3 \mathrm{ab}$ & $13,5 \mathrm{ab}$ \\
$15 \mathrm{~h}$ & $79,0 \mathrm{ab}$ & $31,7 \mathrm{~b}$ & $11,7 \mathrm{ab}$ \\
T1 $^{(2)}$ & $79,0 \mathrm{ab}$ & $44,0 \mathrm{ab}$ & $11,3 \mathrm{ab}$ \\
T2 & $(3)$ & $41,7 \mathrm{ab}$ & $8,8 \mathrm{~b}$ \\
\hline C.V. $\%$ & $53,5 \mathrm{~b}$ & 15,9 & 16,9 \\
\hline
\end{tabular}

(1) Horários de polinização manual.

( $\left.{ }^{2}\right) \mathrm{T} 1=$ testemunha1 (polinização natural, sem proteção da flor).

$\left(^{3}\right)$ T2 = testemunha2 (polinização natural, com proteção da flor).

Médias seguidas pela mesma letra, nas colunas, não diferem estatisticamente pelo teste de Tukey a 5\% de probabilidade. 


\section{CONCLUSÃO}

A polinização natural, sem proteção da flor, foi superior aos demais processos de polinização para fixação de frutos e produção de sementes, não ocorrendo diferenças entre os horários de polinização manual. Possibilitou, ainda, a obtenção de sementes com similares germinação e vigor em relação aos demais processos.

\section{AGRADECIMENTOS}

À FAPESP, pela bolsa de iniciação científica concedida para a primeira autora (processo 02/08644-0).

\section{REFERÊNCIAS}

ÁVILA, C.J.; MARTINHO, M.R.; CAMPOS, J.P. Polinização e polinizadores na produção de frutos e sementes híbridas de abóbora (Cucurbita pepo var. melopepo). Anais da Sociedade Entomológica do Brasil, Campinas, v.18, n.1, p.13-19, 1989.

BEYER, E.M.; QUEBEDEAUX, B. Parthenocarpy in cucumber: mechanism of action of auxin transport inhibitors. Journal of the American Society for Horticultural Science, Alexandria, v.99, n.5, p.385-390, 1974.

BRASIL. Ministério da Agricultura e Reforma Agrária. Regras para análise de sementes. Brasília: SNDA/DNDV/CLAV, 1992. 365p.

CARDOSO, A I. I. Melhoramento de hotaliças. In: NASS, L. L. et al. (Ed). Recursos genéticos e melhoramento de plantas. Rondonópolis: Fundação MT, 2001. cap 12, p.293-326.

DEMPSEY, W.H.; BOYNTON, J.E. Effect of seed number on tomato fruit size and maturity. Journal of the American Society for Horticultural Science, Alexandria, v.86, p.575-581, 1965.

FILGUEIRA, F.A.R. Novo manual de olericultura: agrotecnologia moderna na produção e comercialização de hortaliças. Viçosa: UFV, 2000. 402p.

GEORGE, R.A.T. Vegetable seed production. 2. ed. London: CABI Publishing, 1999. 219p.

KIM, I.S.; OKUBO, H.; FUJIEDA, K. Endogenous levels of IAA in relation to parthenocarpy in cucumber (Cucumis sativus). Scientia Horticulturae, Amsterdam, v.52, p.1-8, 1992.

LOHAR, D. P.; PEAT, W.E. Floral characteristics of heat-tolerant and heat-sensitive tomato (Lycopersicon esculentum Mill.) cultivars at hight temperature. Scientia Horticulturae, Amsterdam, v.73, p.53-60, 1998.

MAGUIRE, J. D. Seed of germination-aid in selection and evaluation for seedling emergence and vigor. Crop Science, Madison, v.2, n.1, p.176-177, 1962.
MALUF, W. R. Heterose e emprego de híbridos F1 em hortaliças. In: NASS, L. L. et al. (ed) Recursos genéticos e melhoramento de plantas. Rondonópolis: Fundação MT, 2001. cap 13, p. 327-355.

MARCELIS, L. F. M.; HOFMAN-EIJER, L. R. B. Effects of seed number on competition and dominance among fruits in Capsicum annuum L. Annals of Botany, London, v.79, n.6, p.687693, 1997.

MARTINS, G. Uso de casa de vegetação com cobertura plástica na tomaticultura de verão. 1992. 65f. Tese (Doutorado em Agronomia)- Faculdade de Ciências Agrárias e Veterinárias, Universidade Estadual Paulista. Jaboticabal.

PASSAM, H. S.; BALTAS, C.; BOYIATZOGLOU, A.; KHAH, E. M. Flower morphology and number of aubergine (Solanum melongena L.) in relation to fruit load and auxin application. Scientia Horticulturae, Amsterdam, v.89, p.309-316, 2001.

POULOS, J. M. Pepper breeding (Capsicum spp.): achievements, challenges and possibilities. Plant Breeding Abstracts, Farnham Royal, v. 64, n.2, p.143-155, 1994.

SHIPP, J. L.;WHITFIELD, G. H.; PAPADOPOUlOS, A. P. Effectiveness of the bumble bee, Bombus impatiens $\mathrm{Cr}$. (Hymenoptera: Apidae), as pollinator of greenhouse sweet pepper. Scientia Horticulturae, Amsterdam, v.57, p.29-39, 1994.

SCHLICHTING, C. D.; DAVIS, L. E.; STEPHENSON, A. G.; WINSOR, J. A. Pollen competition and offspring variance. Evolutionary Trends in Plants, New York, v.1, n.1, p.35-39, 1987.

STEPHENSON, A. G.; DEVLIN, B.; HORTON, J. B. The effects of seed number and prior fruit dominance on the pattern of fruit production in Cucurbita pepo (zucchini squash). Annals of Botany, London, v.62, n.6, p. 653-661, 1988.

SUN, W.; WANG, D.; WU, Z.; ZHI, J. Seasonal change of fruit setting in eggplants (Solanum melongena L.) caused by different climatic conditions. Scientia Horticulturae, Amsterdam, v.44, p.55-59, 1990.

TRANI, P.E.; MELO, A.M.T.; PASSOS, F.A.; TAVARES, M.; NAGAI, H.; SCIVITTARO, W.B. Recomendações de adubação e calagem para berinjela, jiló, pimenta-hortícola e pimentão. In.: RAIJ, B. van; CANTARELLA, H.; QUAGGIO, J.A.; FURLANI, A.M.C. (Ed). Recomendações de adubação e calagem para o Estado de São Paulo. 2 ed. Campinas: IAC, 1996, p.173. 